\title{
SYNTHESIS, CHARACTERIZATION, SURFACE FUNCTIONALIZATION OF MAGNETITE NANOPARTICLES AND THEIR ANTIBACTERIAL STUDIES
}

\author{
Jaiveer Singh, Arti Jangra, Jai Kumar, Keerti Rani and Ramesh Kumar ${ }^{*}$ \\ Department of Chemistry, Kurukshetra University, Kurukshetra-136119, (Haryana) India \\ *E-mail: rameshkumarkuk@gmail.com
}

\begin{abstract}
In the present paper the synthesis of magnetite nanoparticles and their surface functionalization with protein has been described. Surface functionalization of these nanoparticles was confirmed using various techniques including Transmission Electron Microscopy, X-Ray Diffraction, Vibrating Scanning Magnetometry, Thermo-gravimetric studies and Fourier Transform Infrared Spectroscopy. Further, surface-functionalized magnetite nanoparticles were loaded with ciprofloxacin drug and then screened for their antibacterial activity against two gram-positive (Bacillus subtilis and Staphylococcus aureus) and two gram-negative (Pseudomonas aeruginosa and Escherichia coli) bacterial strains.

Keywords: Nanoparticles, Surface Functionalization, Antibacterial Activity, Ciprofloxacin, Fourier Transform Infrared Spectroscopy.

(C) RASĀYAN. All rights reserved

\section{INTRODUCTION}

Nanoscience has been emerged as one of the most significant scientific research areas in the new century due to its potential applications in various industries including food, farming and pharmaceutical. ${ }^{1-3}$ Nanoparticles may be synthesized using various cost-effective and eco-friendly methods such as sol-gel method, green synthesis and nanoprecipitation technique. ${ }^{4-7}$ Surface functionalized magnetite nanoparticles have become more popular among researchers due to their vast applications. The surface functionalization of magnetite nanoparticles with protein enhances the capabilities of these nanoparticles. Biopolymers including proteins have some superb features including biocompatibility which makes them superior to synthetic polymers for the development of nanocarriers. ${ }^{8}$ Artificial nanoparticles combined with biopolymers such as proteins become compatible with the human body. Proteins coating additionally provide nanoparticles with many bioactive features like biodegradability and nontoxicity. ${ }^{9}$ Apart from that, protein-mediated nanoparticles have been found more efficient nanocarriers to deliver the low molecular-weight drugs. ${ }^{10}$ Prompted from these studies, in the present paper, synthesis and characterization of protein-mediated magnetite nanoparticles have been discussed. In addition to that, these functionalized MNPs were loaded with CPF drug. Furthermore, these CPF loaded protein functionalized MNPs were evaluated for their biological activity against four test bacteria.
\end{abstract}

\section{Materials and Methods \\ Reagents}

All the chemicals purchased were of analytical grade and used without further purification. Ferrous sulfate $\left(\mathrm{FeSO}_{4} .7 \mathrm{H}_{2} \mathrm{O}\right)$, ferric chloride $\left(\mathrm{FeCl}_{3} \cdot 6 \mathrm{H}_{2} \mathrm{O}\right)$, ciprofloxacin, hydrochloric acid and ammonia were purchased from SRL (India). Deionized water was used whenever required.

\section{Instruments}

Rigaku Ultima IV fully automatic high-resolution X-Ray Diffractometer system with theta-theta goniometer, Philips CM 200 transmission electron microscope, MB-3000 ABB spectrophotometer.

Rasayan J. Chem., 13(1), 105-111(2020)

http://dx.doi.org/10.31788/RJC.2020.1315382

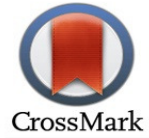




\section{Preparation of Magnetite Nanoparticles}

The co-precipitation method was used for synthesizing bare and functionalized magnetite nanoparticles as reported in previous work. ${ }^{11}$ In brief, $50 \mathrm{ml}$ of ferrous sulphate solution $(0.5 \mathrm{M})$ was mixed with $50 \mathrm{ml}$ of ferric chloride solution $(1.0 \mathrm{M})$. The resulting mixture was heated to $85^{\circ} \mathrm{C}$ with simultaneous stirring at high speed under the continuous supply of nitrogen. After that, the $\mathrm{pH}$ of the solution was raised to $\sim 10.0$ by the addition of ammonia solution into the reaction mixture where MNPs were precipitated. The formation of these magnetite nanoparticles was confirmed by the transformation of the color of the solution from brown to black. The precipitated magnetite nanoparticles were washed many times with deionized water. These magnetite nanoparticles were dried in a vacuum oven at $25^{\circ} \mathrm{C}$. The synthesis of magnetite nanoparticles may be represented as follows. ${ }^{12,13}$

$$
\mathrm{Fe}^{2+}+2 \mathrm{Fe}^{3+}+8 \mathrm{OH}^{-} \longrightarrow \mathrm{Fe}_{3} \mathrm{O}_{4}+4 \mathrm{H}_{2} \mathrm{O}
$$

\section{Surface Functionalization of MNPs with Protein}

The surface of synthesized MNPs was functionalized with protein. Firstly, the protein was dissolved in water to produce a stable emulsion. This, so formed emulsion was added to a well-dispersed solution of magnetite nanoparticles followed by gentle shaking. These protein treated MNPs were finally washed and dried.

\section{CPF loaded EA-MNPs (CPF@EA-MNPs)}

The surface-functionalized MNPs were added to a $100 \mathrm{ml}$ solution of ciprofloxacin drug and allowed to shake very gently. During this process, CPF drug gets loaded on the surface of functionalized MNPs. After that, these drug-loaded nanoparticles were washed and dried in vacuum. The comparison of IR spectra of Ciprofloxacin and CPF loaded EA-MNPs confirmed the loading of CPF on the surface of EAMNPs.

\section{Antimicrobial Assay}

Antibacterial Studies of Ciprofloxacin and CPF Loaded Protein Functionalized Magnetite Nanoparticles (CPF@EA-MNPs)

Autoclave sterilized glassware $\left(121^{\circ} \mathrm{C}, 15 \mathrm{~min}\right)$ was used for the experiments. The agar well diffusion method was used for the evaluation of antibacterial studies i.e after 24 hours of incubation at $37^{\circ} \mathrm{C}$, the samples were assessed for the screening of growth of inhibition zone.

\section{FTIR Spectral Studies}

\section{RESULTS AND DISCUSSION}

The FTIR spectral technique was used for the confirmation of surface functionalization of MNPs and CPF loading on the surface of functionalized MNPs. The comparative study of FTIR spectra of bare magnetite nanoparticles, pure egg albumin protein and protein-coated magnetite nanoparticles confirms the coating of egg albumin on the surface of magnetite nanoparticles. The FTIR spectrum of magnetite nanoparticles show absorption band below $600 \mathrm{~cm}^{-1}$ (Fe-O stretching) and $3400 \mathrm{~cm}^{-1}\left(\mathrm{O}-\mathrm{H}\right.$ stretching) ${ }^{14}$. In FTIR spectrum of Egg Albumin functionalized magnetite nanoparticles new peaks were observed at $3278 \mathrm{~cm}^{-}$ ${ }_{1}^{1} 1643 \mathrm{~cm}^{-1}, 1519 \mathrm{~cm}^{-1}$ and $1080 \mathrm{~cm}^{-1}$. These new peaks observed in the FTIR spectrum of egg-albumin coated magnetite nanoparticles were similar to those observed in the FTIR spectrum of pure egg-albumin protein $^{15}$. Thus, the appearance of these new peaks in the FTIR spectrum of EA-MNPs confirms the coating of egg albumin protein on the surface of $\mathrm{MNPs}^{16}$ (Fig.-1a). Similarly, the comparison between FTIR spectra of pure CPF and CPF@EA-MNPs led us to conclude that CPF has been successfully loaded on the surface of EA-MNPs (Fig.-1b).

\section{Transmission Electron Microscopic Studies}

TEM studies of bare MNPs and EA-MNPs confirms the coating of egg albumin protein on the surface of magnetite nanoparticles as EA-MNPs have an average size of about $20 \mathrm{~nm}$ (Fig.-2a) whereas the average 
RASĀYAN J. Chem.

Vol. 13 | No. 1 |105 - 111| January - March | 2020

size of bare MNPs was only $10 \mathrm{~nm}$ (Fig.-2b). The increased size of EA-MNPs confirms the coating of protein on the surface of bare MNPs.

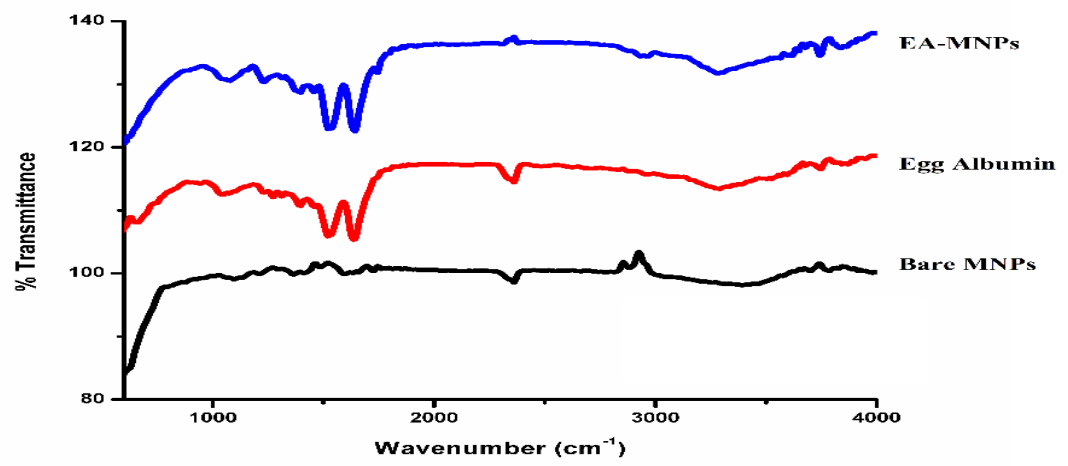

Fig.-1a: FTIR Spectra of Bare MNPs, Egg Albumin and EA-MNPs

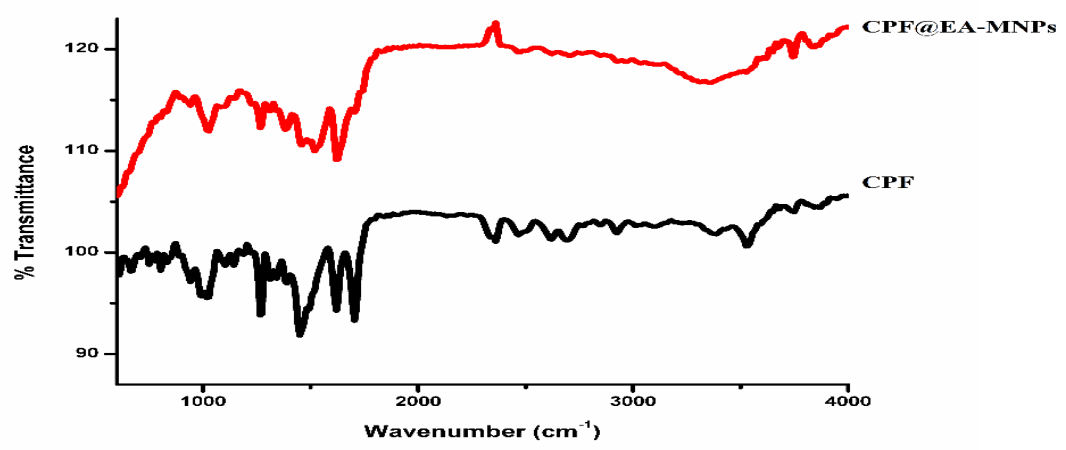

Fig.-1b: FTIR Spectra of CPF and CPF@EA-MNPs

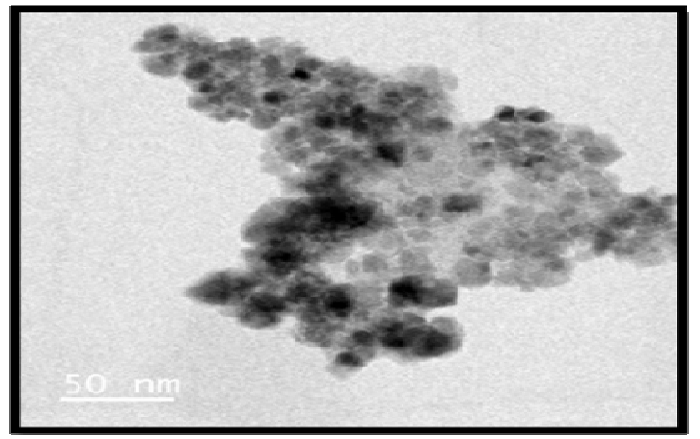

Fig.-2a: TEM image of EA-MNPs

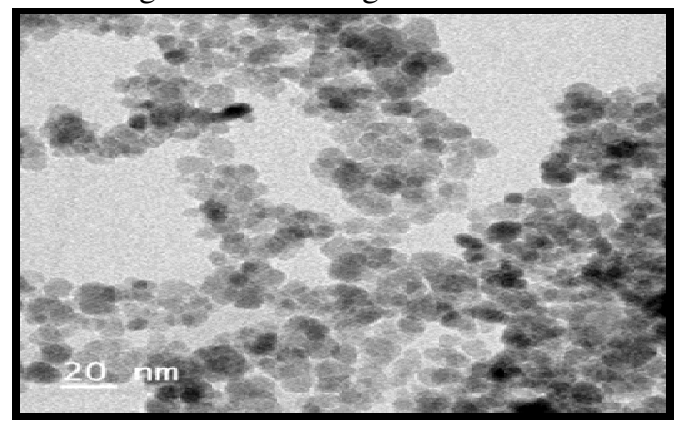

Fig.-2b: TEM image of Bare-MNPs 
RASĀYAN J. Chem.

Vol. 13 | No. 1 |105 - 111| January - March | 2020

\section{XRD Studies of MNPs and EA-MNPs}

The data for the diffraction pattern was collected in a range of $20^{\circ}$ to $50^{\circ}$ with a counting rate of $2 \mathrm{~s} / \mathrm{steps}$ and a step increment of 0.020 . The diffraction plots for bare and surface coated MNPs are shown in (Fig.$3 \mathrm{a}$ and $3 \mathrm{~b}$ ), respectively. The semi-crystalline nature of these MNPs was confirmed from the high-pitched crystalline peaks ${ }^{17}$ observed in the XRD pattern of bare magnetite nanoparticles at $(2 \theta=22.90,30.04$, $35.36,43.02)$.
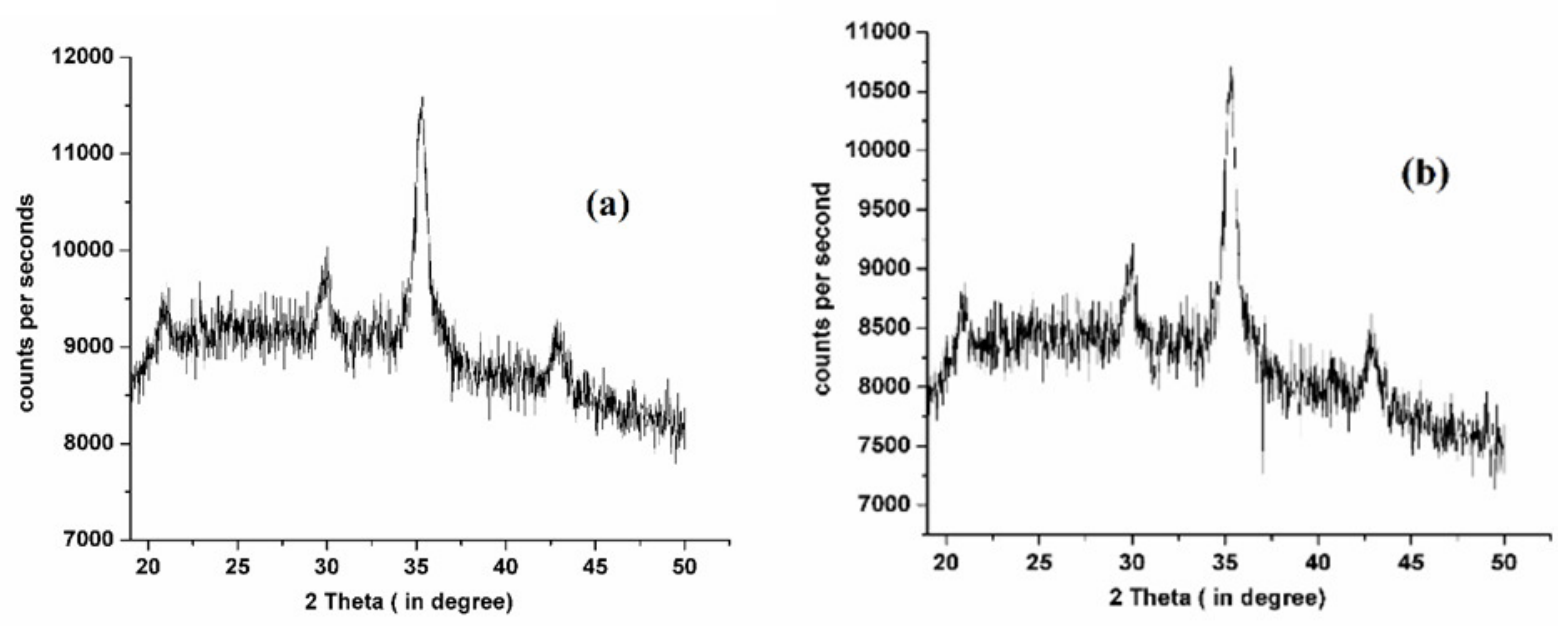

Fig.-3: XRD Plot of (a) Bare and (b) Protein Coated Magnetite Nanoparticles

Similarly, the characteristic peaks were obtained for the coated magnetite nanoparticles at $(2 \theta=22.90$, $30.04,35.32,42.88$ ). The particle size (D) for these uncoated and coated nanoparticles was also determined with the help of Debye-Scherrer's equation $(D=K \lambda / \beta \cos \theta)$, Where, $D$ is the average size of the particles, $\mathrm{K}$ is shape factor having a constant value of $0.91, \lambda$ is the wavelength of $\mathrm{X}$-ray $(\lambda=0.15406$ $\mathrm{nm}), \beta$ is the line width at half of the maximum intensity (FWHM) and $\theta$ being the Bragg's diffraction angle. In this study, the particle size for the bare and coated MNPs was found to be $12.5 \mathrm{~nm}$ and $36.8 \mathrm{~nm}$, respectively. The difference in the size of bare and coated MNPs confirms the coating of protein on the surface of MNPs. Furthermore, the size of bare and coated MNPs determined using Debye-Scherrer's equation are in close agreement with the results obtained from TEM studies for this purpose.

\section{Magnetic Properties of MNPs}

The VSM plots of both bare and coated magnetite nanoparticles (Fig.-4a and $4 \mathrm{~b}$ ) indicate their superparamagnetic behavior as the coercivity or remanence was found to be nil in the magnetic loops of both VSM plots. These studies were carried out at room temperature under the applied magnetic field in the range $+10,000$ to $-10,000$ Oe.
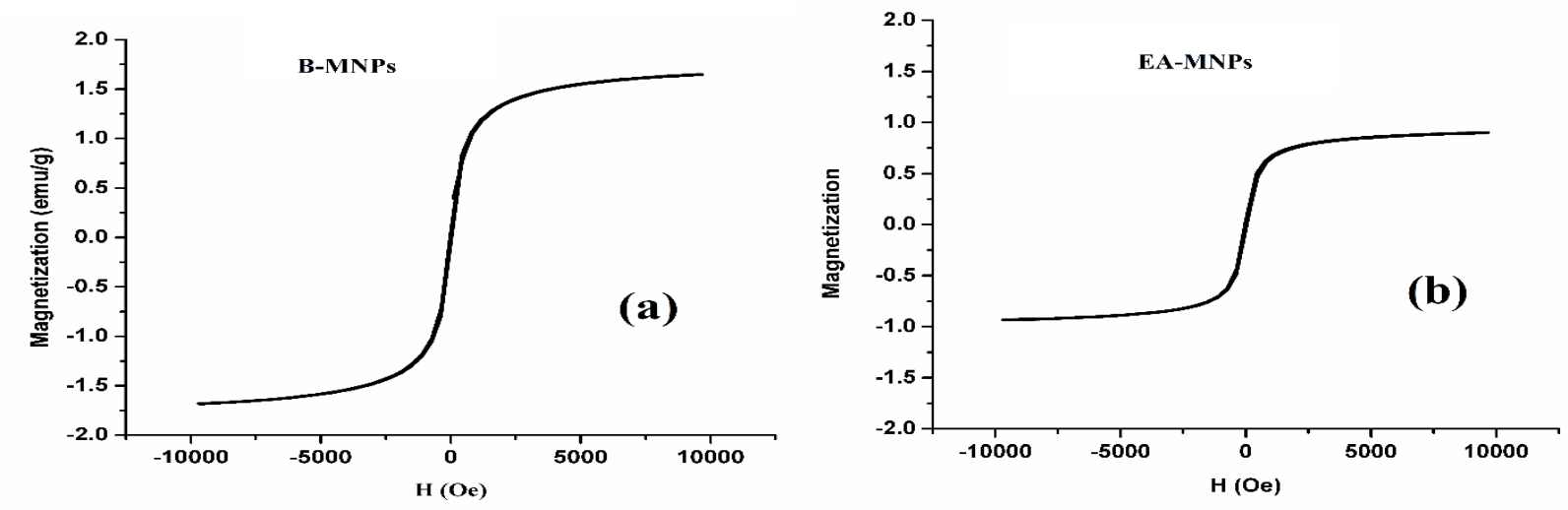

Fig.-4: VSM Plot of (a) Bare and (b) Coated MNPs 
RASĀYAN J. Chem.

Vol. 13 | No. 1 |105 - 111| January - March | 2020

The plots of $\mathrm{M}$ versus $1 / \mathrm{H}$ were extrapolated to zero in order to obtain the magnetic saturation (Ms) values for bare and coated MNPs. A net value of zero was found for the magnetization in absence of external magnetic field. At $10 \mathrm{kOe}$, Ms for bare MNPs was found to be $1.65 \mathrm{emu} / \mathrm{g}$ (Fig.-5a) whereas this value for EA-MNPs was found to be $0.91 \mathrm{emu} / \mathrm{g}$ (Fig.-5b), which is comparatively lesser than that for the bare MNPs.
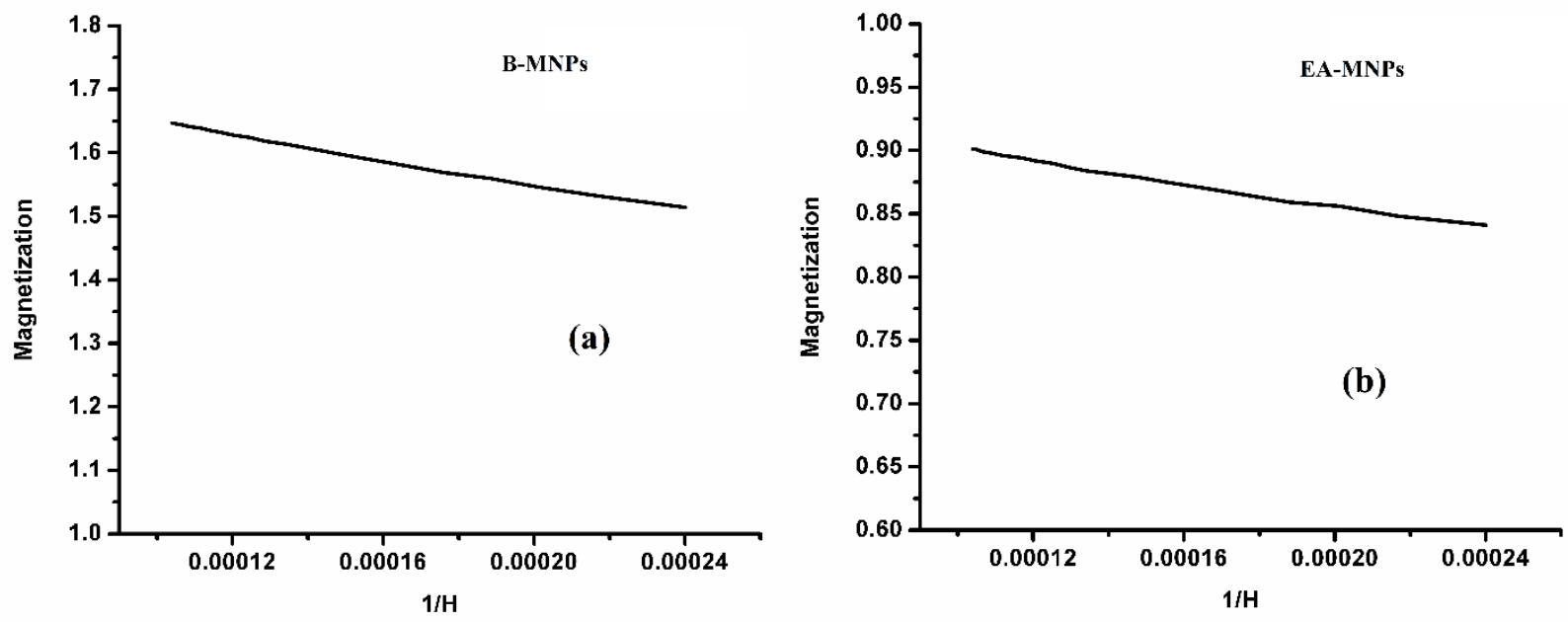

Fig.-5: Magnetic Saturation Plot of (a) Bare and (b) EA-MNPs

This decrease in the magnetization value of the EA-MNPs may be attributed to the fact that material (protein) used for the coating of MNPs is of nonmagnetic nature. However, the coating of protein on MNPs did not significantly diminish the magnetic property of bare magnetite nanoparticles as there is a minor difference in saturation magnetization $\left(\mathrm{M}_{\mathrm{s}}\right)$ values of bare MNPs and EA-MNPs. A comparison of the $\mathrm{M}_{\mathrm{s}}$ value (emu/g) of uncoated and EA-coated MNPs suggested that the content of protein in coated MNPs was about 45\%. Further, from the VSM study, it is clear that the superparamagnetic nature still persists in coated MNPs and thus can be used for targeted drug delivery under the effect of external magnetic field ${ }^{18}$.

\section{Thermogravimetric Studies}

TGA curve of coated MNPs (Fig.-6) suggests a weight loss of about $6 \%$ near $100^{\circ} \mathrm{C}$ which indicates the removal of moisture.

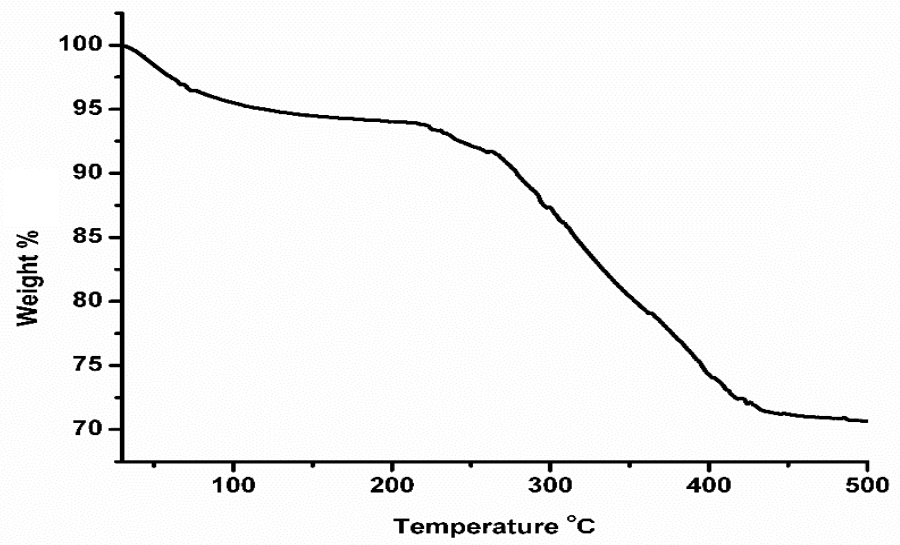

Fig.-6: TGA plot of EA-MNPs

From the above-shown curve, it is clear that thermal degradation of the surface coating material of coated MNPs started at temperature $225^{\circ} \mathrm{C}$ and continued up to $440^{\circ} \mathrm{C}$, with $25 \%$ weight loss. After this temperature, no more changes were observed. This reduction in mass could be explained due to the 
RASĀYAN J. Chem.

Vol. 13 | No. 1 |105 - 111| January - March | 2020

burning of the coating layer of MNPs. ${ }^{19}$ However, these changes were not observed in the case of bare MNPs as reported in a previous paper. ${ }^{11}$ These studies clearly suggest the presence of coating material i.e. protein on the surface of MNPs.

\section{Biological Activity of CPF@EA-MNPs}

The antibacterial activity shown by CPF@EA-MNPs was compared with that of CPF drug against the same bacterial strains. It was observed that the zone of inhibition is greater in the case of CPF@EAMNPs (Table-1) indicating their increased antibacterial activity.

Table-1: In vitro Antibacterial Activity of CPF and CPF@EA-MNPs Using Agar Well Diffusion Method

\begin{tabular}{c|c|c|c|c}
\hline \multirow{2}{*}{ Compounds } & \multicolumn{3}{|c}{ Diameter of Zone of Inhibition (mm) } \\
\cline { 2 - 5 } & \multicolumn{2}{|c}{ Gram +ve Bacteria } & \multicolumn{2}{c}{ Gram -ve Bacteria } \\
\cline { 2 - 5 } & Bacillus subtilis & $\begin{array}{c}\text { Staphylococcus } \\
\text { aureus }\end{array}$ & $\begin{array}{c}\text { Pseudomonas } \\
\text { aeruginosa }\end{array}$ & Escherichia coli \\
\hline CPF & 32 & 25 & 28 & 25 \\
\hline CPF@EA-MNPs & 36 & 27 & 30 & 35 \\
\hline
\end{tabular}

\section{CONCLUSION}

In the present work, superparamagnetic MNPs were synthesized and their surface was functionalized with protein. Different techniques including the IR spectrum and TGA confirmed the coating on the surface of MNPs. Further, it was observed that after functionalization, the superparamagnetic behavior was not changed significantly. Hence the magnetic property of these MNPs may be used even after their surface modification. In addition to that, CPF loaded EA-MNPs were also tested for their antibacterial activity. It was found that there is a small increment in antibacterial activity as compared to that of standard drugs. This effect may be attributed to the increased surface to volume ratio in the case of CPF loaded EAMNPs.

\section{ACKNOWLEDGMENTS}

Co-authors Jaiveer Singh, Arti Jangra, Jai Kumar and Keerti Rani are highly thankful to Kurukshetra University, Kurukshetra for providing necessary research facilities. One of the authors (Jaiveer Singh) is also thankful to UGC, New Delhi for providing financial support.

\section{REFERENCES}

1. P. Sanguansri and M.A. Augustin, Trends in Food Science \& Technology, 17(10), 547(2006), DOI:10.1016/j.tifs.2006.04.010

2. S. Sabir, M. Arshad and S.K. Chaudhari, The Scientific World Journal, 925494, 8 pages (2014), DOI: $10.1155 / 2014 / 925494$

3. T. Neuberger, B. Schopf, H. Hofmann, M. Hofmann and B.V. Rechenberg, Journal of Magnetism and Magnetic Materials, 293(1), 483(2005), DOI: 10.1016/j.jmmm.2005.01.064

4. G.M. Srirangam and K.P. Rao, Rasayan Journal of Chemistry, 10(1), 46(2017), DOI: 10.7324/RJC.2017.1011548

5. C.T. Handoko, A. Huda, M.D. Bustan, B. Yudono and F. Gulo, Rasayan Journal of Chemistry, 10(4), 1137(2017), DOI: 10.7324/RJC.2017.1041875

6. P. Senthilkumar, S.S. Dawn, C. Saipriya and A.V. Samrot, Rasayan Journal of Chemistry, 11(4), 1686 (2018), DOI: 10.31788/RJC.2018.1144053

7. I. Fatimah, S. Fadhilah, Yulan and S.A. Mawardani, Rasayan Journal of Chemistry, 11(2), 544(2018), DOI: 10.7324/RJC.2018.1122067

8. S.K. Nitta and K. Numata, International Journal of Molecular Sciences, 14(1), 1629 (2013), DOI: $10.3390 /$ ijms 14011629

9. K.S. Soppimath, T.M. Aminabhavi, A.R. Kulkarni and W.E. Rudzinski, Journal of Controlled Release, 70(1-2), 1(2001), DOI: 10.1186/1477-3155-9-55 
RASĀYAN J. Chem.

Vol. 13 | No. 1 |105 - 111| January - March | 2020

10. A.O. Elzoghby, W.M. Samy and N.A. Elgindy, Journal of Controlled Release, 161(1), 38(2012) DOI: 10.1016/j.jconrel.2012.04.036

11. R. Kumar, B.S. Inbaraj and B.H. Chen, Materials Research Bulletin, 45(11), 1603(2010) DOI: 10.1016/j.materresbull.2010.07.017

12. C. Fu and N.M. Ravindra, Bioinspired, Biomimetic and Nanobiomaterials, 1(BBN4), 229(2012) DOI:10.1680/bbn.12.00014

13. H. Karami, Journal of Cluster Science, 21(1), 11(2010), DOI:10.1007/s10876-009-0278-x

14. M. Nadeem, M. Ahmad, M.S. Akhtar, A. Shaari, S. Riaz, S. Naseem, M. Masood and M. Saeed, PloS one, 11, e0158084(2016), DOI:10.1371/journal.pone.0158084

15. X.Y. Tian, J. Wen, J. Hu, Z. Chen, S. Wang, H. Peng and J. Li, Solid State Sciences, 59, 39(2016), DOI: 10.1016/j.solidstatesciences.2016.07.006

16. P.Y. Furlan, S.A. Scott and M.S. Peaslee, Spectroscopy Letters, 40, 475(2007), DOI: 10.1080/00387010701295950

17. X. Sun, C. Zheng, F. Zhang, Y. Yang, G. Wu, A. Yu and N. Guan, The Journal of Physical Chemistry C, 113(36), 16002(2009), DOI:10.1021/jp9038682

18. I. Karimzadeh, M. Aghazadeh, T. Doroudi, M.R. Ganjali and P.H. Kolivand, Advances in Physical Chemistry, 9437487, 7 pages (2017), DOI:10.1155/2017/9437487

19. P. Thangaraj, J. Rajan, S. Durai, S. Kumar, A. RatnaPhani and G. Neri, Vacuum, 86(2), 140(2011), DOI:10.1016/j.vacuum.2011.05.001

[RJC-5382/2019] 